\title{
Pediatric Prolonged Mechanical Ventilation: Considerations for Definitional Criteria
}

\author{
Michaël Sauthier MD, Louise Rose RN PhD, and Philippe Jouvet MD PhD
}

\begin{abstract}
BACKGROUND: A 2005 consensus conference led by the National Association for Medical Direction of Respiratory Care (NAMDRC) defined prolonged mechanical ventilation (PMV) for adults as invasive and/or noninvasive mechanical ventilation (NIV) for $\geq 21$ consecutive days for $\geq 6 \mathrm{~h} / \mathrm{d}$. In children, no such consensus definition exists. This results in substantial variability in definitional criteria, making study of the impact and outcomes of PMV across and within settings problematic. The objective of this work was to identify how PMV for children and neonates is described in the literature and to outline pediatric/neonatal considerations related to PMV, with the goal of proposing a pediatric/neonatal adaptation to the NAMDRC definition. METHODS: We searched electronic databases for studies describing PMV in children. We extracted definitional criteria and developed recommendations based on the literature review and our clinical experience. RESULTS: Of the 416 citations obtained, 87 met inclusion criteria, totaling 34,255 subjects. Identified criteria for the pediatric PMV definition included: number of consecutive days of mechanical ventilation (ranging from $6 \mathrm{~h}$ to 3 months), inclusion of NIV, time spent off the ventilator during weaning (considered as same ventilation episode), and importance of chronological age (term neonates) and postmenstrual age for preterm neonates. We considered high-flow nasal cannula; however, we determined that its current role as a weaning adjunct is unclear. CONCLUSIONS: Therefore, we developed the following recommendations for the pediatric PMV definition: $\geq 21$ consecutive days (after 37 weeks postmenstrual age) of ventilation for $\geq 6 \mathrm{~h} / \mathrm{d}$ considering invasive ventilation and NIV and including short interruptions $(<48 \mathrm{~h})$ of ventilation during the weaning process as the same episode of ventilation. We propose a definition of pediatric PMV that incorporates the number of consecutive days of mechanical ventilation while taking into account use of NIV and lung maturity and including short interruptions during the weaning process. Key words: mechanical ventilation; prolonged mechanical ventilation; neonates; children; intensive care; critical care. [Respir Care 2017;62(1):49-53. (C 2017 Daedalus Enterprises]
\end{abstract}

\section{Introduction}

Mechanical ventilation is a common treatment in intensive care, whether for neonates, children, or adults. Independent of the underlying disease, this supportive treat-

\footnotetext{
Drs Sauthier and Jouvet are affiliated with the Research Center of SainteJustine Hospital and the Pediatric ICU, Sainte-Justine Hospital, Montreal, Québec, Canada. Dr Rose is affiliated with the Department of Critical Care, Sunnybrook Health Sciences Centre, the Sunnybrook Research Institute, the Lawrence S Bloomberg Faculty of Nursing and Interdepartmental Division of Critical Care Medicine, University of Toronto, the Provincial Centre of Weaning Excellence/Prolonged Ventilation Weaning Centre, Toronto East General Hospital, and the Li Ka Shing Knowledge Institute, St. Michael's Hospital, Toronto, Ontario, Canada.
}

ment is associated with many complications that may prolong its duration, such as ventilator-associated lung in-

\footnotetext{
Dr Rose has disclosed a relationship with the Canadian Institutes of Health. Dr Jouvet has disclosed a relationship with the Health Research Agency of Quebec (FRQS). Dr Sauthier has disclosed no conflicts of interest.

Supplementary material related to this paper is available at http:// www.rcjournal.com.

Correspondence: Philippe Jouvet MD PhD, Soins Intensifs Pédiatriques, Hôpital Sainte-Justine, 3175 Chemin Côte Sainte-Catherine, Montréal, Québec H3T 1C5, Canada. E-mail: philippe.jouvet@umontreal.ca.
}

DOI: $10.4187 /$ respcare.04881 
jury and pneumonia. Health-care costs associated with intensive care are projected to increase as a result of more patients requiring prolonged mechanical ventilation (PMV). ${ }^{1}$ In 2005, a consensus conference led by the National Association for Medical Direction of Respiratory Care (NAMDRC) defined PMV for adults as mechanical ventilation for $\geq 21$ consecutive days for $\geq 6 \mathrm{~h} / \mathrm{d}$ of invasive (via endotracheal tube or tracheostomy) and/or noninvasive (facial/nasal interface) methods of delivery. ${ }^{2}$ In children, 10 years after the published NAMDRC definition, no such consensus definition exists, making it difficult to interpret study results describing a PMV population and to determine the impact of PMV across and within settings.

The absence of a pediatric PMV definition has resulted in: (1) substantial variability in duration of ventilation described as PMV in the published literature, with duration generally ranging from $2-7 \mathrm{~d}^{3-5}$ to $21-28 \mathrm{~d}^{6-9}$ (these 2 groups may be derived from the perspective of pediatric intensivists who want to differentiate between patients who are able to be extubated quickly and longer-term ICU patients and of pediatric pulmonologists who may be making decisions about home mechanical ventilation support; (2) lack of standardization regarding the inclusion of noninvasive ventilation (NIV) in the definition; (3) lack of standardization regarding the inclusion of times when the child is ventilator-free during weaning (ie, should these contribute to the number of days of consecutive ventilation?); and (4) no specific considerations for neonates in relation to when to commence counting the number of consecutive days that define PMV (ie, at which age, chronological or postmenstrual). ${ }^{7-10}$ Therefore, there is an urgent need to standardize the definition of PMV in children to: (1) describe the epidemiology of PMV; (2) assist clinicians with reprioritizing goals of care and the type of information to share with patients and their families ${ }^{10}$; and (3) identify effective interventions that will reduce the number of children requiring PMV. In this perspective, we propose an operational definition of pediatric PMV based on relevant literature and the authors' clinical experience.

\section{Methods}

In February 2016, we searched the Cochrane Central Register of Controlled Trials (CENTRAL), MEDLINE (2000 to February 2016), and EMBASE (2000 to February 2016) using the following search terms: prolonged, protracted, chronic, sustained, increased length, or long term mechanical ventilation. Criteria were determined a priori, and studies were eligible for inclusion if they included mechanically ventilated (invasive and NIV) children or neonates, including mixed adult and pediatric cohorts. Exclusion criteria included: case reports, case series of $<10$ patients, commentary or editorials, and non-peer-reviewed

\section{QUICK LOOK}

\section{Current knowledge}

The pediatric prolonged mechanical ventilation definition has not yet been defined and results in substantial variability in definitional criteria.

\section{What this paper contributes to our knowledge}

The authors reviewed literature and report that pediatric prolonged mechanical ventilation definition that can be used is defined by $\geq 21$ consecutive days (after 37 weeks postmenstrual age) of ventilation for more than 6 hours per day including invasive and noninvasive ventilation duration and short interruptions $(<48 \mathrm{~h})$ of ventilation during the weaning process as the same episode of ventilation.

articles. Articles written in a language other than English were not included. We extracted the definitional criteria used to identify the study cohort as PMV and any rationale reported for the definitional criteria used.

\section{Results and Discussion}

Of the 416 citations obtained, 87 met inclusion criteria (see the supplementary materials at http://www.rcjournal.com), totaling 34,255 subjects. Criteria used to define PMV were heterogeneous. Most of the articles (77\%) defined PMV by a time criterion (ie, the duration of mechanical ventilation). However, there was no consensus as to the duration, with ranges varying from $6 \mathrm{~h}$ to 3 months (Fig. 1), with shorter duration ( $\geq 4 \mathrm{~d}$ ) for surgical as opposed to medical patients ( $\geq 7$ or $21 \mathrm{~d}$, with $21 \mathrm{~d}$ used by the most recent studies). Other studies defined PMV as the presence of a tracheostomy, receiving ventilation at home, or receiving ventilation in a care center dedicated to chronic ventilation.

\section{What Duration of Ventilation Should Be Used for PMV in Children?}

In the NAMDRC PMV definition, ${ }^{2} 21$ consecutive days of mechanical ventilation was chosen for the adult population. Moreover, $21 \mathrm{~d}$ of ventilatory support has been used to define PMV in pediatric literature ${ }^{6,7}$ and may correspond to a turning point in the goals of care and type of weaning strategies to be used. Another advantage of this definition is that it offers objectivity, uniformity, and simplicity in terms of identifying the patient cohort. ${ }^{11}$ It corresponds to $2.5-3 \%$ of the population admitted to pediatric ICUs $^{4,7}$ and represents a cohort of ventilated children who 


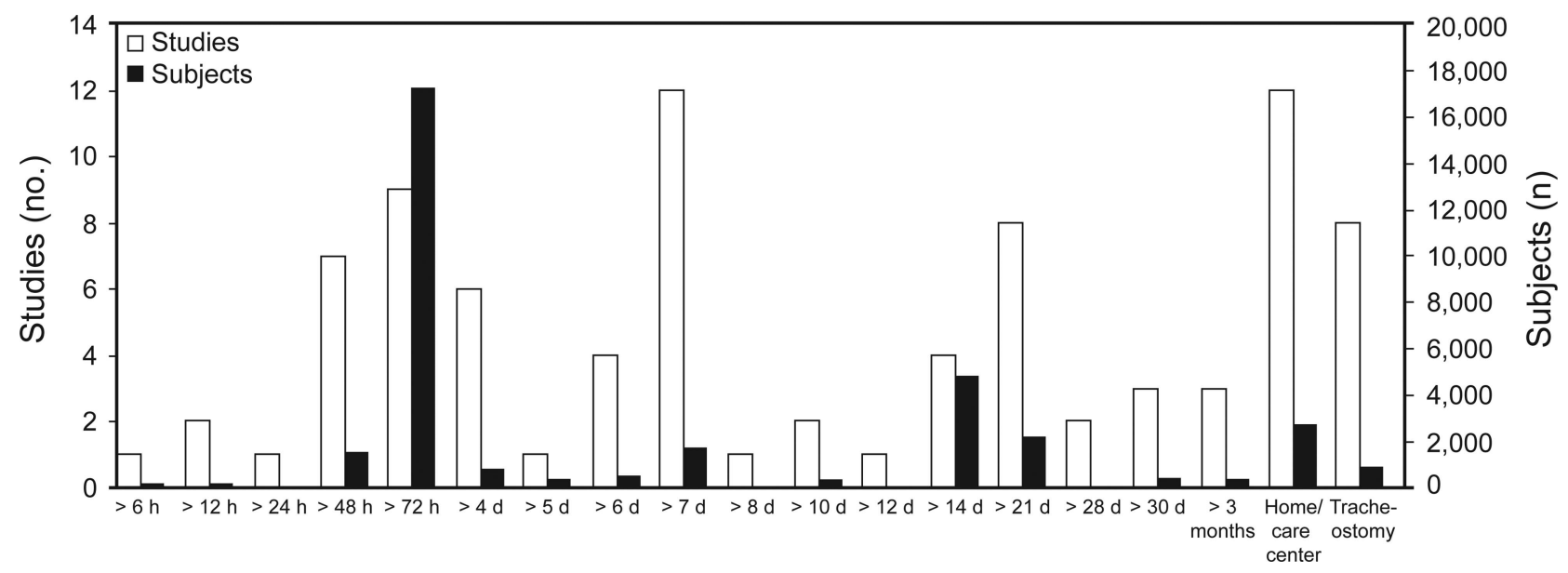

Fig. 1. Duration of mechanical ventilation used to describe prolonged mechanical ventilation.

need rehabilitation strategies ${ }^{12}$ to promote weaning success and generally have a tracheotomy in place if they require invasive ventilation. ${ }^{13,14}$

\section{How Should Short Episodes Off the Ventilator During Weaning Affect Establishment of PMV as Defined as $21 \mathrm{~d}$ of Consecutive Ventilation?}

In our systematic review, few studies 4,7 discussed the time off the ventilator during weaning. The NAMDRC PMV definition recommends this term be applied to patients receiving mechanical ventilation for $\geq 21$ consecutive days for $\geq 6 \mathrm{~h} / \mathrm{d}$. However, if clinically indicated during these $21 \mathrm{~d}$, weaning trials may occur with patients removed from any form of ventilatory support for up to $48 \mathrm{~h}$ before the establishment of weaning success. ${ }^{2}$ Patients who fail weaning will be returned to ventilatory support; however, this means that there has been an interruption in the number of consecutive days of mechanical ventilation. Therefore, we propose that in the case of weaning failure (defined as the need to recommence ventilation within $48 \mathrm{~h}$ before $21 \mathrm{~d}$ of ventilation), the days off ventilatory support should be included in the number of consecutive days of mechanical ventilation used to define pediatric PMV (see Fig. 2C). Infants with lung fragility (eg, bronchopulmonary dysplasia) may be at risk of more than one PMV episode in their life. For simplicity and uniformity reasons, we argue that the duration on and off the ventilator in the pediatric PMV definition should not be modulated by patient history and comorbidities.

\section{Should HFNC Be Included in the Number of Consecutive Days of Ventilatory Support to Establish Pediatric PMV?}

The NAMDRC definition of adult PMV recommended that NIV be included in the number of consecutive days of

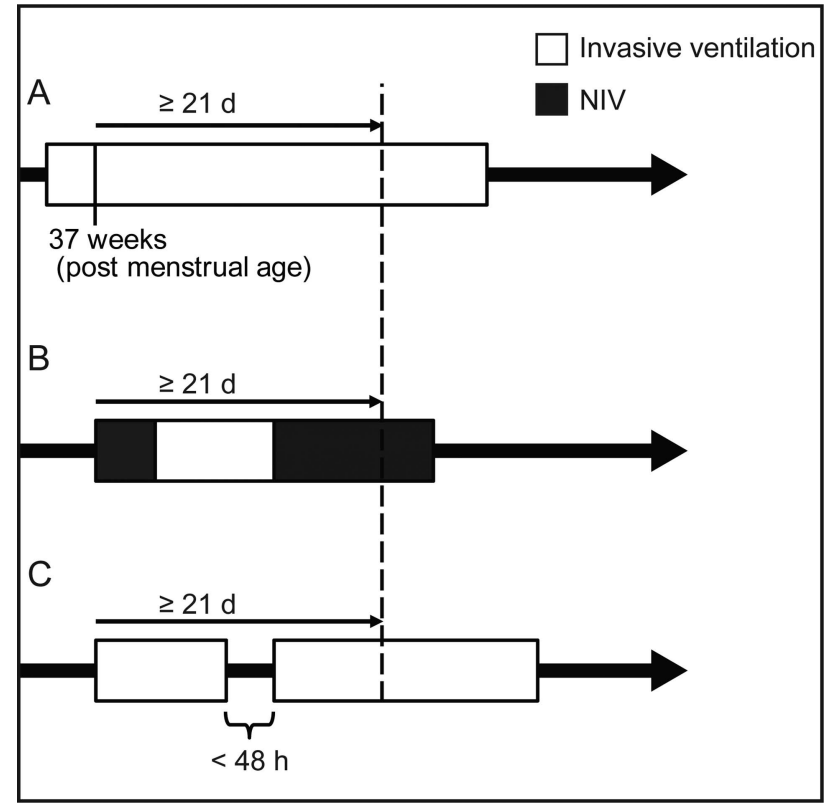

Fig. 2. Schematic representation of the proposed definition of prolonged mechanical ventilation (PMV) in neonates and children. A: Definition of PMV in neonates older than 37 weeks postmenstrual age. B: Different ventilation modes included in the PMV definition for children. C: Weaning failure $<48 \mathrm{~h}$ before $21 \mathrm{~d}$ counted as the same episode of respiratory support. The dotted vertical line shows the demarcation for PMV.

mechanical ventilation, which we support for inclusion of pediatric PMV. However, the role of high-flow nasal cannula (HFNC) was not discussed, and at that time, few data were available on the physiological benefits of HFNC. At present, although there are limited and equivocal data suggesting that HFNC generates PEEP in adults, the evidence seems stronger in the pediatric population. In children, HFNC has been demonstrated to generate PEEP between 4 and $6 \mathrm{~cm} \mathrm{H}_{2} \mathrm{O}$ with gas flows $>1.7 \mathrm{~L} / \mathrm{min} / \mathrm{kg} .{ }^{15-18} \mathrm{In}$ adults, HFNC generates a more unpredictable and less 


\section{Definition of Prolonged Pediatric Mechanical Ventilation}

marked increase of PEEP that ranges from 1.5 to $5 \mathrm{~cm} \mathrm{H}_{2} \mathrm{O} .{ }^{19,20} \mathrm{HFNC}$ decreases work of breathing in all age groups, whether it is measured by the electrical activity of the diaphragm, ${ }^{16}$ pressure rate product, ${ }^{21}$ or clinical scores or vital signs, ${ }^{15}$ even when no respiratory failure is present. ${ }^{16}$ The risk of intubation with HFNC is similar to NIV and significantly lower than using standard nasal cannula for neonates. ${ }^{22}$ Despite all of these data, inclusion of HFNC in the pediatric PMV definition is still a source of debate, and we advocate that this issue be discussed in a consensus conference.

\section{When Defining Pediatric PMV Do We Use the Chronological Age or the Corrected Age for Neonates?}

Preterm birth is defined by the World Health Organization as neonates born alive before 37 weeks of pregnancy. In neonates, age can be counted according to chronological age (age from birth) or using the corrected age defined as the chronological age reduced by the number of weeks born before 40 weeks of gestation; the term should be used only for children $\leq 3$ y of age who were born preterm. ${ }^{23}$ Corrected age takes into account the maturation stage of the newborn that includes neurological, cardiovascular, and respiratory development and is considered important as a defining feature of other definitions. For example, bronchopulmonary dysplasia is diagnosed by the ongoing need of supplemental oxygen at different time points depending on the postmenstrual age (gestational age plus chronological age) and gestational age. ${ }^{24}$ Neonates born before 32 weeks gestational age may be diagnosed with bronchopulmonary dysplasia at 36 weeks postmenstrual age; those born at $\geq 32$ weeks gestational age may be diagnosed using the chronological age from 4 to 8 weeks of life. We propose that the definition of pediatric PMV use chronological age when the cohort is homogeneous in terms of gestational age (eg, preterm neonates of 28 weeks gestational age). However, if a cohort includes premature and term neonates, the usual case in pediatric ICUs, the corrected age should be used to standardize the maturation stage of neonates. In such a heterogeneous cohort, the duration of ventilation before 37 weeks gestational age would not count toward the 21 consecutive days of ventilation. This means that the definition of pediatric PMV could not be applied before 40 weeks gestational age (see Fig. 2A). To illustrate this operational definition of pediatric PMV, here are 3 cases. (1) A 5-month-old girl who was born at 24 weeks (1-month-old corrected age or 44 weeks postmenstrual age) is transferred from the neonatal unit to the pediatric ICU (Fig. 2A). She was intubated from birth to 38 weeks postmenstrual age and was successfully weaned from invasive ventilation to NIV after a second hydrocortisone treatment at 40 weeks postmenstrual age. She is still receiving NIV $22 \mathrm{~h}$ on 24 (total of
Table 1. Proposed Criteria for Pediatric Prolonged Mechanical Ventilation

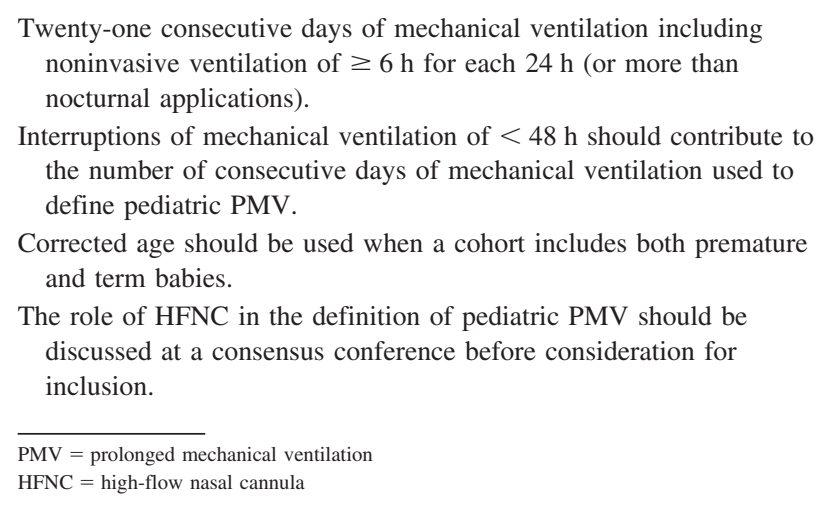

5 months of mechanical ventilation; 7 weeks [44 37 weeks] if corrected age is used). (2) A 7-y-old boy was admitted to the ICU for pneumonia and required NIV support (Fig. 2B). On the second day, he was intubated for severe oxygenation failure. After $7 \mathrm{~d}$ of invasive mechanical ventilation, he was extubated. Two hours later, NIV was commenced due to increased work of breathing. $\mathrm{He}$ was subsequently reintubated because of severe $\mathrm{CO}_{2}$ retention. Ten days later, he was extubated to NIV and was successfully weaned from mechanical ventilation after $4 \mathrm{~d}$ (total $23 \mathrm{~d}$ of mechanical ventilation). (3) A 10-y-old boy who was intubated for Guillain-Barré syndrome was extubated on day 6 of mechanical ventilation (Fig. 2C). Thirty-six hours later, he was unable to protect his airway and required reintubation. Two weeks later, he was successfully extubated (total $22 \mathrm{~d}$ of mechanical ventilation).

\section{Summary}

We have highlighted important issues for consideration in the establishment of a pediatric PMV definition, namely determination of $\geq 21$ consecutive days of mechanical ventilation (after 37 weeks postmenstrual age) of ventilation for $\geq 6 \mathrm{~h}$ each day considering invasive and NIV and including short interruptions $(<48 \mathrm{~h}$ ) of ventilation during the weaning process as the same episode of ventilation (Table 1). To gain consensus and subsequent adoption of this definition, we plan to host a consensus conference with international experts representing pediatric intensive care, neonatal intensive care, and the pediatric pulmonology community. We will refine this definition by discussing the relevance to different patient populations (eg, chronic lung disease, neuromuscular disease, congenital heart defect) and debating the role of weaning adjuncts, such as HFNC, to come to a final consensus. 


\section{Definition of Prolonged Pediatric Mechanical Ventilation}

\section{REFERENCES}

1. Zilberberg MD, Shorr AF. Prolonged acute mechanical ventilation and hospital bed utilization in 2020 in the United States: implications for budgets, plant and personnel planning. BMC Health Serv Res 2008;8:242.

2. MacIntyre NR, Epstein SK, Carson S, Scheinhorn D, Christopher K, Muldoon S, and National Association for Medical Direction of Respiratory Care. Management of patients requiring prolonged mechanical ventilation: report of a NAMDRC consensus conference. Chest 2005;128(6):3937-3954.

3. Wakeham MK, Kuhn EM, Lee KJ, McCrory MC, Scanlon MC. Use of tracheostomy in the PICU among patients requiring prolonged mechanical ventilation. Intensive Care Med 2014;40(6):863-870.

4. Payen V, Jouvet P, Lacroix J, Ducruet T, Gauvin F. Risk factors associated with increased length of mechanical ventilation in children. Pediatr Crit Care Med 2012;13(2):152-157.

5. Polito A, Patorno E, Costello JM, Salvin JW, Emani SM, Rajagopal $\mathrm{S}$, et al. Perioperative factors associated with prolonged mechanical ventilation after complex congenital heart surgery. Pediatr Crit Care Med 2011;12(3):e122-e126.

6. Monteverde E, Fernández A, Poterala R, Vidal N, Siaba Serrate A, Castelani $\mathrm{P}$, et al. Characterization of pediatric patients receiving prolonged mechanical ventilation. Pediatr Crit Care Med 2011;12(6): e287-e291.

7. Traiber C, Piva JP, Fritsher CC, Garcia PC, Lago PM, Trotta EA, et al. Profile and consequences of children requiring prolonged mechanical ventilation in three Brazilian pediatric intensive care units. Pediatr Crit Care Med 2009;10(3):375-380.

8. Thomas M, Greenough A, Morton M. Prolonged ventilation and intact survival in very low birth weight infants. Eur J Pediatr 2003; 162(2):65-67.

9. Fraser J, Henrichsen T, Mok Q, Tasker RC. Prolonged mechanical ventilation as a consequence of acute illness. Arch Dis Child 1998; 78(3):253-256.

10. Rose L, Fowler RA, Fan E, Fraser I, Leasa D, Mawdsley C, et al. Prolonged mechanical ventilation in Canadian intensive care units: a national survey. J Crit Care 2015;30(1):25-31.

11. Rose L, Fowler RA, Goldstein R, Katz S, Leasa D, Pedersen C, et al. Patient transitions relevant to individuals requiring ongoing ventilatory assistance: a Delphi study. Can Respir J 2014;21(5):287-292.

12. Jubran A, Grant BJ, Duffner LA, Collins EG, Lanuza DM, Hoffman LA, Tobin MJ. Effect of pressure support vs unassisted breathing through a tracheostomy collar on weaning duration in patients requiring prolonged mechanical ventilation: a randomized trial. JAMA 2013;309(7):671-677.

13. Overman AE, Liu M, Kurachek SC, Shreve MR, Maynard RC, Mammel MC, Moore BM. Tracheostomy for infants requiring prolonged mechanical ventilation: 10 years' experience. Pediatrics 2013;131(5): e1491-e1496.

14. Holloway AJ, Spaeder MC, Basu S. Association of timing of tracheostomy on clinical outcomes in PICU patients. Pediatr Crit Care Med 2015;16(3):e52-e58.

15. Spentzas T, Minarik M, Patters AB, Vinson B, Stidham G. Children with respiratory distress treated with high-flow nasal cannula. J Intensive Care Med 2009;24(5):323-328.

16. Pham TM, O'Malley L, Mayfield S, Martin S, Schibler A. The effect of high flow nasal cannula therapy on the work of breathing in infants with bronchiolitis. Pediatr Pulmonol 2015;50(7):713-720.

17. Milési C, Baleine J, Matecki S, Durand S, Combes C, Novais AR, et al. Is treatment with a high flow nasal cannula effective in acute viral bronchiolitis? A physiologic study. Intensive Care Med 2013; 39(6): 1088-1094.

18. Hough JL, Pham TM, Schibler A. Physiologic effect of high-flow nasal cannula in infants with bronchiolitis. Pediatr Crit Care Med 2014;15(5):e214-e219.

19. Sotello D, Rivas M, Mulkey Z, Nugent K. High-flow nasal cannula oxygen in adult patients: a narrative review. Am J Med Sci 2015; 349(2):179-185.

20. Sztrymf B, Messika J, Bertrand F, Hurel D, Leon R, Dreyfuss D, Ricard JD. Beneficial effects of humidified high flow nasal oxygen in critical care patients: a prospective pilot study. Intensive Care Med 2011;37(11):1780-1786.

21. Rubin S, Ghuman A, Deakers T, Khemani R, Ross P, Newth CJ. Effort of breathing in children receiving high-flow nasal cannula. Pediatr Crit Care Med 2014;15(1):1-6.

22. Lee JH, Rehder KJ, Williford L, Cheifetz IM, Turner DA. Use of high flow nasal cannula in critically ill infants, children, and adults: a critical review of the literature. Intensive Care Med 2013;39(2): 247-257.

23. Engle WA, American Academy of Pediatrics Committee on Fetus and Newborn. Age terminology during the perinatal period. Pediatrics 2004;114(5):1362-1364.

24. Jobe AH, Bancalari E. Bronchopulmonary dysplasia. Am J Respir Crit Care Med 2001;163(7):1723-1729. 